\title{
Factors Affecting Cervical Cancer Screening among Women Below 25 Years in Kithare Area, Tharaka Nithi County, Kenya
}

\author{
D. Mugambi Ngari'1,2, Machwara S. Nyamiaka' ${ }^{1}$, Fridah M. Mukami² \\ ${ }^{1}$ Kenyatta University, Nairobi, Kenya \\ ${ }^{2}$ Chuka University, Chuka, Kenya \\ Email: dennisngare@gmail.com, sethmachwara@gmail.com, fridahmukami14@gmail.com
}

How to cite this paper: Ngari, D.M., Nyamiaka, M.S. and Mukami, F.M. (2021) Factors Affecting Cervical Cancer Screening among Women Below 25 Years in Kithare Area, Tharaka Nithi County, Kenya. Open Journal of Obstetrics and Gynecology, 11, 485-503.

https://doi.org/10.4236/ojog.2021.115046

Received: March 12, 2021

Accepted: May 7, 2021

Published: May 10, 2021

Copyright $\odot 2021$ by author(s) and Scientific Research Publishing Inc. This work is licensed under the Creative Commons Attribution International License (CC BY 4.0).

http://creativecommons.org/licenses/by/4.0/

(c) (i) Open Access

\begin{abstract}
Cervical cancer is the most common neoplasm among women globally affecting approximately 500,000 women with 275,000 succumbing to the disease every year. The prevalence of cervical cancer is disproportionately high in sub-Saharan Africa where the screening rate is low. The study sought to assess the factors affecting cervical cancer screening among women aged 15 25 years in Kithare area Tharaka Nithi County. The study was a descriptive cross-sectional study and interviewer administered questionnaires were used to capture the level of knowledge, individual perspectives, attitude and barriers influencing cervical cancer screening. This study was conducted between August and September 2018 with the sample size being 80 respondents. From the findings a significant number of women had two or more sexual partners. The level of knowledge on cervical cancer was significantly low as $(55 \%, \mathrm{n}=$ 44) were aware about the disease, $(45 \%, \mathrm{n}=36)$ had the correct knowledge when to seek screening, $(40 \%, \mathrm{n}=32)$ knew the correct interval for attending screening and only $(18.7 \%, \mathrm{n}=15)$ had been screened before. Reasons for seeking screening for the $18.7 \%$ were to know their health status, due to abnormal discharge or as a result of bleeding. $(86.3 \%, \mathrm{n}=69)$ believed that screening was helpful with reasons being; for early detection of the disease, to know the health status, to prevent infertility and death. $(13.7 \%, \mathrm{n}=11)$ believed that screening was not helpful with reasons being; the procedure is uncomfortable, painful, it leads to a low self-esteem, fear of wrong results and the diagnosis of cancer. Barriers citied to cervical cancer screening were; inadequate knowledge, negative attitude towards screening, lack of the screening services and cost of services. The knowledge and practice of cervical cancer screening was inadequate. More education on screening should be provided to reduce the misconceptions involved. Provision of free services and
\end{abstract}


more participation in education and sensitization from the healthcare providers should also be done.

\section{Keywords}

Neoplasm, Cervical Cancer, Screening, Mortality

\section{Introduction}

Cervical cancer is a malignant disease that affects the cervix with the attributed causes being the Human Papilloma Virus (HPV) and Herpes Simplex virus whose risk factors are associated with having increased sexual activity from multiple partners [1]. The disease is the easiest gynecologic cancer to prevent, with regular screening tests and follow up. Women below 25 years are at risk of developing cervical cancer. Early screening is essential as it aids in reducing cervical cancer incidences since it allows early diagnosis and treatment. Studies conducted in African countries such as Kenya, Botswana, and Nigeria have shown that women have limited knowledge towards screening of cervical cancer. This contributes to their non-participation in screening programs, and even though some get tested, they do not present themselves up for follow up care [2] [3].

Cervical cancer is the most prevalent type of neoplasm among women globally, and more so, the disease has been rampant in the developing countries with Kenya not being an exemption. Worldwide an estimated 529,828 cases of the disease are reported every year with 275,125 women succumbing to the ailment. According to surveillance and epidemiology, it has been determined that the average life years lost due to cancer of the cervix is approximately 25.3 years [4] [5]. Of the new occurring cases of cervical cancer each year, about 86 percent occur in the developing countries where 85 percent of the mortality occurs. Sub Saharan Africa is the region with the highest incidence of cervical in the world that is; 22 percent of all cases of cervical cancer (CV) with a concomitant high mortality rate from the disease that usually affects women during the prime years of their life's [6]. According to Herweijer et al., this is attributable to the low screening uptake in the region for early detection of precancerous lesions and the onset of the HIV/AIDS epidemic that magnifies the issue [7].

The heavy burden of cervical cancer in the developing nations is as a result of the inadequate prevention approaches that hinder the early detection and subsequent treatment. Very few women from these countries hardly go for cervical cancer screening which is essential for the early detection of the condition [8]. If they ever go for screening it is because they have had issues with their reproductive system and it was recommended by the physician. In fact, most of the women in the developing countries do not have adequate knowledge about the disease. Thus, it becomes difficult to prevent and treat it [9]. The Cancer Research UK (2014) states that health outcomes from cervical cancer in these 
countries are poor due to late diagnosis and treatment. The burden of cervical cancer is increased by inadequate health literacy concerning the disease's pathology, cost of screening, treatment challenges and barriers to seeking health care.

Kenya has a population of 12.92 million women aged 15 years, and above who are at risk of developing cervical cancer thus urgent preventive measures are paramount [9]. Currently, the estimated annual number of cervical cancer cases is 2454 while the annual number of deaths due to cervical cancer is 1676 in Kenya. It is projected that by the year 2025, the number of new cervical cancer cases annually in Kenya will reach 4261 . More so about 39.6 percent of the women in the general population are estimated to harbor the Human Papilloma Virus at a given time that causes the disease [9].

Screening methods available in Kenya that are part of the Ministry of Health $(\mathrm{MOH})$ national cervical cancer prevention strategic plan include the use of Pap smear, visual inspection with acetic acid (VIA) and visual inspection with Lugol's iodine (VILI). Despite the call from the government to adopt these strategies in the fight against cervical cancer, their uptake is very low. Cervical cancer screening coverage in Kenya is currently at 3.2 percent which is very low [9]. This further complicates the situation at hand. Factors that have been associated with the low uptake include lack of awareness, lack of funds, women's worry about the examination discomfort, fear of being diagnosed with cancer and the inability to establish effective follow-up treatment [10].

\section{Objectives of the Study}

\section{Broad Objective}

To determine the factors affecting cervical cancer screening among women aged below 25 years in Kithare area Tharaka Nithi County

\section{Specific Objectives}

1) To assess the level of knowledge on cervical cancer screening among women aged 25 years and below in Kithare area

2) To determine the individual perspectives and attitude about cervical cancer screening

3) To identify the barriers to cervical cancer screening among women aged 25 years and below in Kithare area

\section{Literature Review}

Women have a poor perception and limited knowledge about the need and importance of cervical cancer screening leading to reduced uptake of screening services. Some believe that an abnormal screening result means that the woman already has cancer. Thus, due to the limited knowledge, they opt not to get tested [11]. More so, in most of the communities in the developing countries, women are bound by the cultural norms of secrecy not to discuss reproductive health issues with their families as well as healthcare practitioners hindering the women from gaining knowledge on the importance of cancer screening [12]. 
According to Alfaro et al., having the correct knowledge on the importance of cervical cancer screening is a key determinant for a woman to seek screening services. To increase the screening rate, more efficient educative strategies need to be employed [4]. The use of health educators may be useful in recruiting and scheduling HPV screening appointments. Rasul, Cheraghi, \& Moghdam in a study done to assess the influencing factors on cervical cancer screening among the Kurdish women, beliefs and knowledge on cervical cancer and screening played a significant role in the women's decision making to get screened. Women were more likely to get screened if there were prevailing beliefs about the risk of getting cervical cancer and if they presented with the symptoms [13].

Despite the fact that cervical cancer has a very high mortality rate in the developing countries only a few women will go for screening due to their negative attitude towards the service. Beliefs and perceptions influence the decision on cervical cancer screening [13]. Understanding the factors associated with the women's attitude of cervical cancer could guide future educational planning and clinical interventions to improve cervical cancer screening as this will help in influencing the women positively and increase the uptake rate of screening [14].

A number of women associate cancer with lots of treatment and the final outcome being death. Others view cancer as a death sentence without a cure and therefore; women will evade the cervical cancer test to avoid a positive result. Women who have had at least one cervical cancer test are less likely to express fear and anxiety compared to those who are new. Since the conflicts mentioned above exert a significant effect on the women's tendency to participate in cervical cancer screening, providing precise information about cervical cancer testing is crucial in increasing the willingness of getting tested [15].

Other influences to cervical cancer screening include the social, cultural factors regarding the beliefs and traditions, the perception of testing and religion. Some cultures believe that screening is evil and unclean; therefore, women from these communities will hardly consider going for cervical screening. Some husbands also have a negative attitude towards the practice of cervical screening because they do not want their women and wives to be examined on their reproductive parts. Some tell and assume that their wives go to have some private affairs with other men and consider the practice unclean. Because of the fear of being chased away from their marriages and homes women married from such men do not find cervical cancer screening necessary [9].

Economic constraints are also a factor that influences cervical cancer screening. The woman has to pay for the services offered by the healthcare provider and for those lacking the funds; they will end up missing the screening opportunity. This is one of the contributing reasons why quite a number of women in the developing countries do not go for the screening or for follow up care. For those already diagnosed with cervical cancer treatment is expensive for them to afford and most of the times they end up missing it and will succumb to the disease at the long run [16]. Therefore, it is essential for the government and pri- 
vate organizations to provide help programs to such individuals in an effort of promoting cervical cancer screening and reducing the mortality rate of the disease.

\section{Material and Methods}

Kithare Sub-location is in Chogoria ward or location which has a population of approximately 32,000 residents. The sub-location is in Mwimbi Division, Maara Sub-County in Tharaka Nithi County, Kenya. The population of Kithare sub-location is 3685 residents with more than half of these being women of the reproductive age.

\section{Research Design}

This is a descriptive cross sectional study aimed at determining the factors affecting cervical cancer screening among women aged below 25 years in Kithare area Tharaka Nithi County conducted between August and September 2018.

\section{Study Population and Selection Criteria}

The study population comprised of women of the reproductive age, 15 - 25 years who were residents of Kithare sub-location located in Maara Sub County, Tharaka Nithi County. Why women aged 15 to 25 years because they are sexually active and very prone to get the disease. Only those women who gave a free voluntary informed consent to take part in the study were involved with the sample size being 80 respondents.

\section{Sampling Procedures and Sample Size}

Convenience sampling method was used in the study. The eligible participants who meet the inclusion criteria and give an informed consent to participate in the research study were involved. The sample size was estimated using Cochrane's formula [17] and Fisher's formula [18] with the study participants included in the study being 80 . Kithare Sub-location has nearly 2000 women with nearly $1 / 4$ aged 25 years and below (KDHS, 2016).

\section{Sample Size Calculation}

The sample size was determined using Cochrane's formula.

Where;

$$
n=\frac{z^{2} p q}{d^{2}}
$$

$n=$ sample size if the target population is less than 10,000

$z=$ standard normal deviate corresponding to $95 \%$ confidence level (1.96)

$p=$ proportion of the target population. Since information on the screening prevalence in rural areas is not available, $50 \%(0.5)$ is assumed to get the possible maximum sample size.

$q=1-p$ (Proportion without characteristics): $q=1-p=(1-0.5)=0.5$

$d=$ the level of statistical significance at $95 \%$ confidence level $=(0.05)$

$n=\frac{1.96^{2} \times 0.5 \times 0.5}{0.05^{2}}=384$

$n f$ is the desired sample size and represents the estimate population size which 
is less than 10000 and thus sample size was determined by Fisher's formula

$$
n f=\frac{n}{1+n / N}=\frac{384}{1+384 / 100}=\frac{384}{1+3.84}=\frac{384}{4.84}=79.332
$$

Thus, the study participants included in the study were 80 in number.

\section{Validity and Reliability}

Validity refers to how well a test measures what is purported to measure. Validity was ensured by; Expert review of the instruments (questionnaires) before commencement of the study for content validity. The researcher ensured that all the questions in the instrument were clear, properly grouped and easy to understand. Training of research assistants was done to ensure a proper understanding of the operational definitions of the study and uniformity in the questioning skills.

Reliability is the degree to which an instrument produces conSsistent results if repeated. A pretest of $10 \%$ of sample size was done prior to actual data collection which aided in establishing the reliability by finding out if sufficient questions were included to meet the study objectives and whether the meaning of the questions was similar to all the respondents. After which necessary adjustments were made.

\section{Data Management}

Information from the research participants was collected using interviewer administered questionnaires. Data entry using unique identifiers was done in duplicate for validation (double entry) and the data was crosschecked for entry error. Data Analysis was done using SPSS version 25.0 for windows. Interpretation and presentation was done using line graphs, tables, pie charts and bar graphs.

\section{Results and Discussion}

\subsection{Socio-Demographic Characteristics of the Respondents}

\subsubsection{Age Distribution (Table 1)}

Majority of the respondents $(47.5 \%, \mathrm{n}=38)$ were aged $23-25$ years.

\subsubsection{Level of Education (Figure 1)}

All the respondents had attained some formal education with half of them (50\%, $\mathrm{n}=40$ ) having attained a college level of education.

\section{Occupation (Figure 2)}

Almost half $(42.5 \%, \mathrm{n}=34)$ of the respondents interviewed were students. The occupation of the other respondents included formal employment, business and farming respectively $(23.7 \%, \mathrm{n}=19 ; 17.5 \%, \mathrm{n}=14 ; 16.3 \%, \mathrm{n}=13)$.

\section{Age at First Sexual intercourse (Table 2)}

Majority of the respondents did not remember the ages at their first sexual intercourse $(37.5 \%, \mathrm{n}=30)$. At eighteen years, only $27.5 \%(\mathrm{n}=22)$ reported to have had sex. Thirty five percent of the respondents $(n=28)$ reported to have had their first sexual experience after attaining eighteen years. 
Table 1. Age distribution of the respondents.

\begin{tabular}{ccc}
\hline Age (Years) & Frequency & Percentage \\
\hline $15-18$ & 20 & 25 \\
$19-22$ & 22 & 27.5 \\
$23-25$ & 38 & 47.5 \\
Total & 80 & 100.0 \\
\hline
\end{tabular}

Table 2. Age at first sexual intercourse.

\begin{tabular}{ccc}
\hline Age (Years) & Frequency & Percentage \\
\hline 12 & 8 & 10 \\
15 & 6 & 7.5 \\
16 & 4 & 5 \\
18 & 4 & 5 \\
19 & 12 & 15 \\
20 & 12 & 15 \\
21 & 2 & 2.5 \\
23 & 2 & 2.5 \\
Don't know & 30 & 37.5 \\
Total & 80 & 100.0 \\
\hline
\end{tabular}

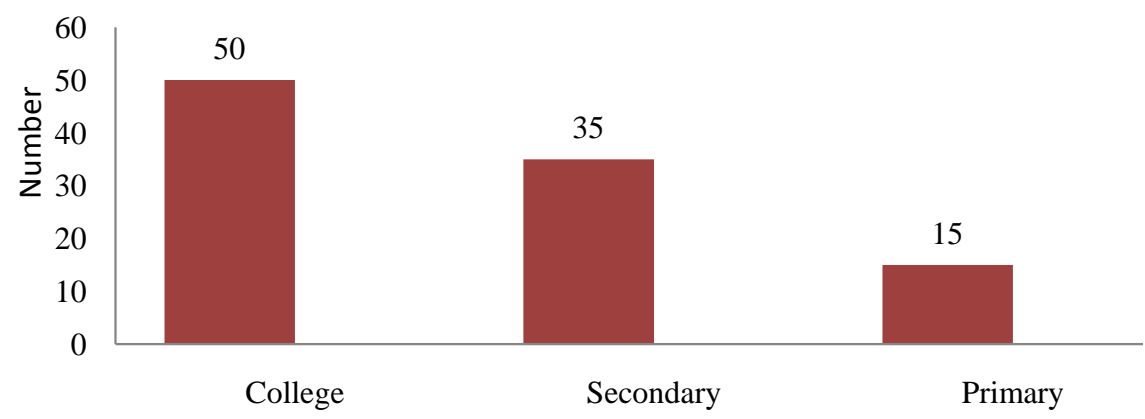

Figure 1. Respondents: level of education.

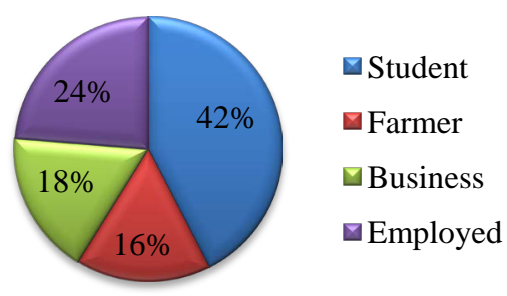

Figure 2. Occupation of the respondents

\section{Number of Sexual Partners (Figure 3)}

Majority of the respondents $37.5 \%(n=30)$ reported to have had one sexual partner while $25 \%(n=20)$ had two or more sexual partners. A significant per- 
centage $(37.5 \%, \mathrm{n}=30)$ said they did not have any sexual partner at the time of the interview.

\subsection{Knowledge on Cervical Cancer Screening}

\section{Whether respondent had heard of cervical cancer (Figure 4)}

Only fifty five percent of the respondents $(n=44)$ reported to have heard about cervical cancer. Not surprisingly, Ntekim states that cervical cancer screening studies conducted in Africa have shown that women have limited knowledge and awareness towards cervical cancer and screening [2].

Respondents Understanding of Cervical Cancer (Figure 5)

Half of the participants $(n=40)$ correctly said that cervical cancer affects the cervix while the rest did not indicating inadequate knowledge on cervical cancer as stipulated by Bosgraaf et al., (2014) [19].

\section{Source of Information on Cervical Cancer Screening (Figure 6)}

Media channels were the major source of information about cervical screening $(47.5 \%, \mathrm{n}=38)$. However, there were relatively few participants $(23.7 \%, \mathrm{n}=19)$ who got information from health facilities. This indicates the need for more

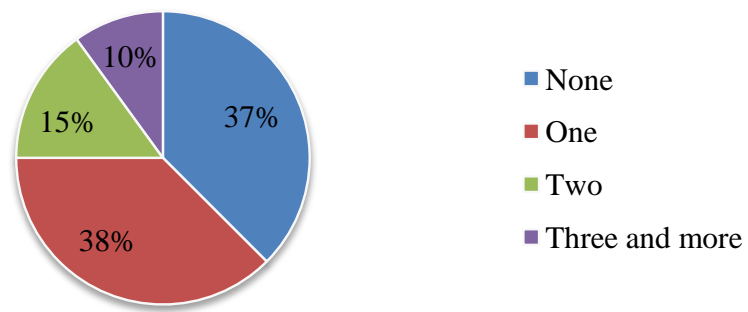

Figure 3. Number of sexual partners.

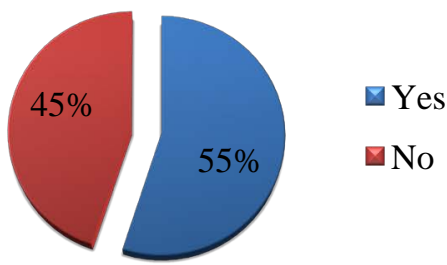

Figure 4. Whether the respondent had heard about cervical cancer.

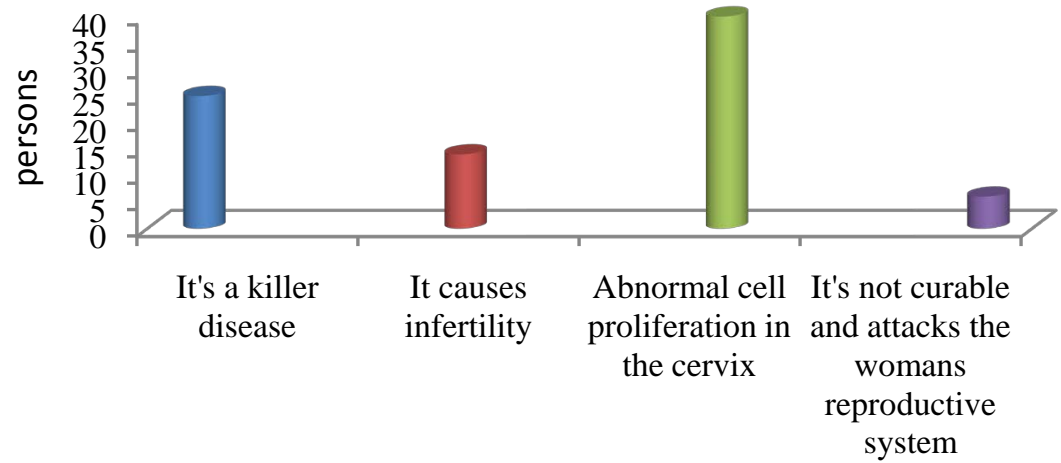

Figure 5. Respondents understanding of cervical cancer. 


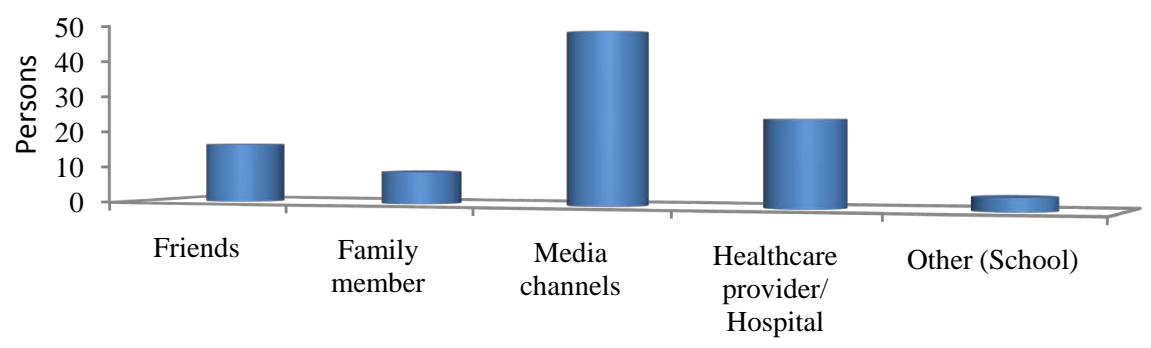

Figure 6. Source of information on cervical cancer.

participation in education and sensitization from healthcare providers in the fight against cervical cancer disease [2].

When a Woman Should Go for Cervical Cancer Screening (Figure 7)

Majority of the participants indicated that women should go for cervical cancer screening when sexually active $(45 \%, \mathrm{n}=36)$. Any woman who is sexually active whether married or not, it is paramount for them to seek screening services [16]. Other reasons cited for going for screening included menstruation $(35 \%, \mathrm{n}=28)$ and marriage $(20 \%, \mathrm{n}=16)$ that were incorrect.

\section{Interval for Attending Cervical Cancer Screening (Table 3)}

From the study results $40 \%(\mathrm{n}=32)$ indicated that screening should be done annually. The interval for attending screening for women aged 25 years and below should be annually [2]. However, a woman should seek screening services as per the healthcare provider instructions especially if they had abnormal results in their first test that was identified correctly by $17.5 \%$ of the study participants. It is crucial to note that this information contradicts with the new cervical cancer screening guidelines that indicate women aged 25 and below should go for screening after every 3 years replacing the previous guideline because when screening is done annually, abnormal cells may be found in this age group that often go away on their own.

\section{Whether the Respondent Had Been Screened before (Figure 8)}

Majority of the participants reported to have never been screened for cervical cancer $(81.3 \%, \mathrm{n}=65)$. Cervical cancer screening coverage in Kenya is currently at 3.2 percent which is very low and this is supported by the study results. The estimated annual number of cervical cancer cases in the country is 2454 while the annual number of deaths due to cervical cancer is 1676 in Kenya because cancer is often detected at the late stages as very few women seek the screening services [20].

\section{Reason for Seeking the Screening Services (Figure 9)}

Among the participants who were screened for cervical $(18.7 \%, n=15)$, eight of them wanted to know their health status, four sought the screening services because of abnormal discharge while three were screened due to excessive vaginal bleeding. According to a WHO report in 2014, women in the developing countries hardly go for cervical cancer screening and if they do it is because they have had issues with their reproductive system and it was recommended by the physician that was demonstrated in the research study [8]. 
Table 3. Interval for attending screening.

\begin{tabular}{ccc}
\hline Interval & Frequency & Percentage \\
\hline Monthly & 18 & 22.5 \\
Annually & 32 & 40 \\
Every 2 years & 5 & 6.3 \\
As per HCP instruction & 14 & 17.5 \\
Do not know & 11 & 13.7 \\
Total & 80 & 100.0 \\
\hline
\end{tabular}

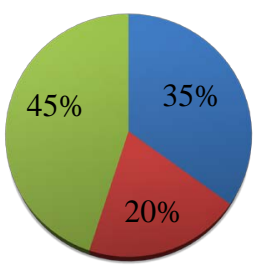

- When starting menstruation

- When married

- When sexually active

Figure 7. When a woman should go for cervical cancer screening.

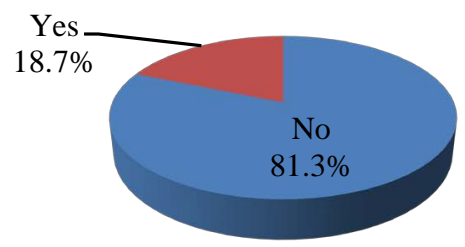

Figure 8. Whether the respondent had been screened before.

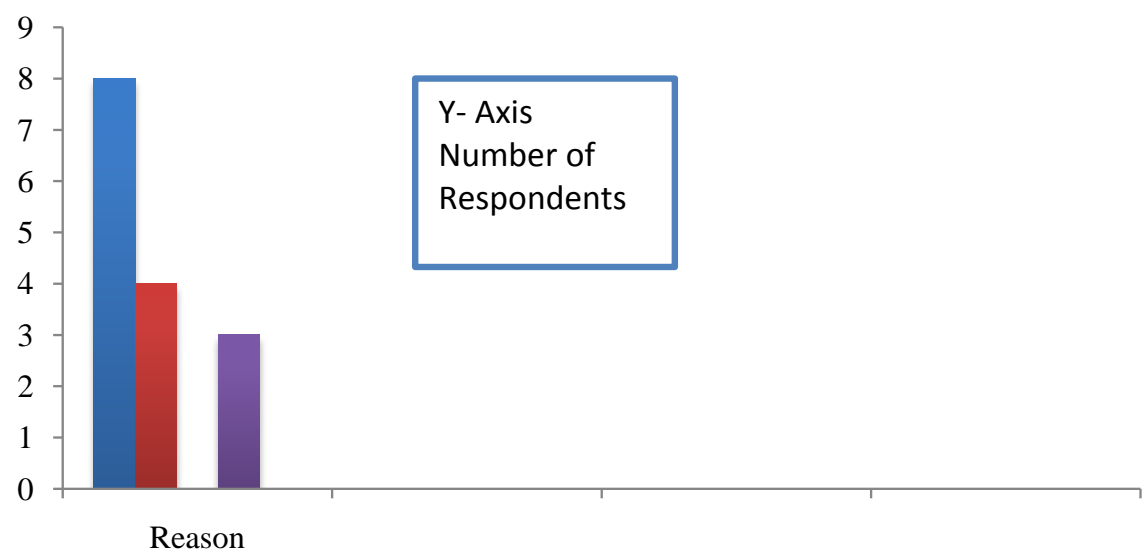

Figure 9. Reason for seeking screening services.

\subsection{Individual Perspectives and Attitude about Cervical Cancer Screening}

Understanding as to whether Cervical Cancer Screening is Helpful (Figure 10)

Beliefs and perceptions influence the decision on cervical cancer screening. Majority of the participants $(86.3 \%, \mathrm{n}=69)$ believed that cervical cancer screening is helpful. 
(Table 4) From the sixty nine respondents who agreed that cervical cancer screening is important, the cumulative reasons cited included; early detection and management $(n=45)$, knowing own health status $(n=26)$, prevention of death $(n=13)$ and prevention of infertility $(n=12)$. Despite the fact that quite a majority of the respondents were in an agreement that screening was beneficial, a number of the women associated cancer with death. This is supported by work done by Guilfoyle, Franco and Gorin that revealed that a diagnosis of cancer is linked to a death sentence therefore; women will evade the cervical cancer test to avoid a positive result. Thus, providing precise information about the cervical cancer test is crucial to increase the willingness to have the test [15].

(Figure 11) From the 11 respondents who believed that cervical cancer screening was not helpful, the cumulative reasons given included; pain and discomfort $(n=7)$, fear of the procedure $(n=3)$, fear of wrong diagnosis $(n=2)$ and low self-esteem $(\mathrm{n}=2)$. Sandeep states that when a woman is making a decision to go for cervical cancer screening she deals with a series of inner thoughts, conflicts

Table 4. Reasons why cervical cancer screening is important.

\begin{tabular}{cc}
\hline Reason & Frequency \\
\hline It prevents Infertility & 12 \\
For early detection and management & 45 \\
Prevent death & 13 \\
Helps to know health status & 26 \\
Total responses & 96 \\
\hline
\end{tabular}

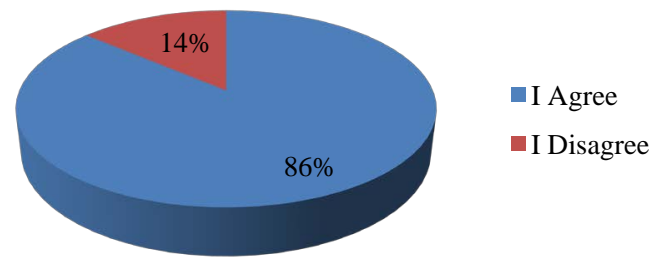

Figure 10. Understanding as to whether cervical cancer screening is helpful.

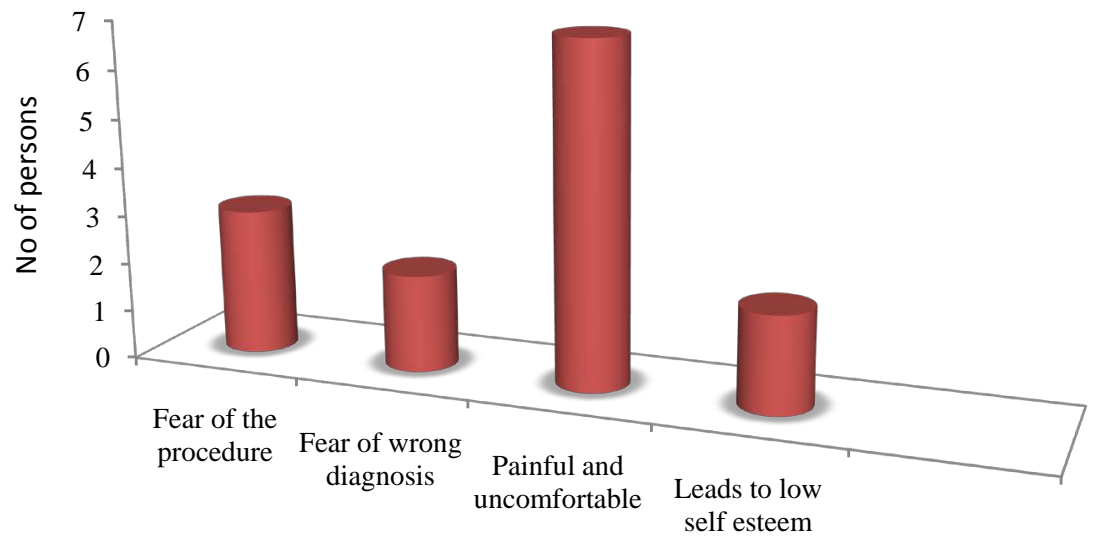

Figure 11. Reasons why it is not helpful. 
and worries. A woman getting screened has to cope with the fears and anxieties associated with the test. In addition to their fear of pain and that of unknown pathology, the woman worries about the possibility of being diagnosed with cancer [21]. Thus, in avoiding this emotional trauma, most of the women will not go for screening.

\subsection{Barriers that Hinder Cervical Cancer Screening (Table 5)}

The most citied barriers to cervical cancer screening included; inadequate knowledge $(\mathrm{n}=54)$, negative attitude towards screening $(\mathrm{n}=42)$, lack of the screening services $(n=41)$ and inadequate finances $(n=34)$. Other reasons cited included culture $(n=13)$, religion $(n=12)$, lack of support $(n=11)$ and male spouse disapproval $(\mathrm{n}=9)$. Inadequate knowledge by women about cervical cancer was cited as a major reason as supported by a study done by Aminisani, Fattahpour, Abedi, \& Shamshirgaran that reveals that increased knowledge about cervical cancer and the importance of screening leads to a positive perception regarding the health promotion and disease prevention and creates an accurate base for correct beliefs about the cervical cancer tests [22]. When women have limited awareness and misconceptions on cervical cancer screening tests, they hardly go to get screened.

Cultural and religious beliefs towards screening, male spouse disapproval and lack of support were cited as challenges hindering cervical cancer screening. According to Rosser et al., some cultures believe that screening is evil and unclean; therefore, women from these communities will hardly go for the test. Some husbands also have a negative attitude towards the practice as they do not want their women and wives to be examined on their reproductive parts [23]. Inadequate money for seeking screening services was also cited as a major hindrance to screening by 34 respondents. Most of the people in Kenya a developing county live below 1 dollar per day and will not afford funds for screening services. The woman has to pay for the services offered by the healthcare provider and for those lacking the funds; they will end up missing the screening opportunity. For

Table 5. Barriers for cervical cancer screening.

\begin{tabular}{cc} 
Barrier & Frequency \\
\hline Lack of screening services & 41 \\
Inadequate knowledge by women & 54 \\
Inadequate money for screening & 34 \\
Negative attitude towards screening & 42 \\
Cultural beliefs against screening & 13 \\
Religious beliefs against screening & 12 \\
Lack of male/family support & 11 \\
Male spouse disapproval & 9 \\
Total responses & 216 \\
\hline
\end{tabular}


Table 6. Measures to improve the practice of cervical cancer screening.

\begin{tabular}{cc}
\hline Measure & Frequency \\
\hline Enhancing public awareness on cervical cancer & 49 \\
Provision of free screening services & 26 \\
More education on the importance of screening & 31 \\
Provision of more services & 14 \\
Increasing the screening equipment & 8 \\
Increasing the healthcare facilities with the service & 9 \\
Seminars and outreach programs for healthcare providers & 5 \\
Enhancing family support & 3 \\
Total responses & 145 \\
\hline
\end{tabular}

those already diagnosed with cervical cancer treatment is expensive for them to afford and most of the times they end up missing it and will succumb to the disease at the long run [16].

Lack of screening services and inaccessibility problems were cited as challenges hindering the practice of cervical cancer screening by 41 respondents. Arbynet al., states that despite having limited facilities offering the services, there are no experts or the required equipment for screening [24]. Gebreegziabher et al., supports inaccessibility as a significant barrier towards cervical cancer screening [25]. From the barriers raised in relation to cervical cancer screening appropriate measures need to be taken to improve the practice.

Measures to improve the practice of Cervical Cancer Screening (Table 6)

Concerning the improvement of cervical cancer screening, the main measures suggested by the participants' included; enhancing public awareness on cervical cancer $(n=49)$, enhancing education (31) and providing free screening services $(\mathrm{n}=26)$

\section{Conclusion}

From the study, the researcher made the following conclusions: The age at first sexual intercourse ranged from 12 to 23 years with a significant number of the women reporting that they had two or more sexual partners thus were at risk of cervical cancer. The knowledge and practice of cervical cancer screening were inadequate. In relation to the individual's perspectives about screening some women believed that it was important for early detection and management of the disease, to know the health status, it is important in preventing infertility and death. On the contrary, others were afraid of the procedure, some citied the procedure to be uncomfortable and painful, it leads to a low self-esteem as well as the fear of wrong results and the diagnosis of cancer. Inadequate knowledge, lack of screening services, negative attitude towards screening and limited funds were cited as major barriers towards screening. Other barriers citied include cultural and religious beliefs towards screening, male spouse disapproval and 
lack of support.

\section{Study Limitations}

Language barrier was a significant challenge when administering the questionnaire as most of the participants conversed in their local native language.

\section{Recommendations}

More education on screening should be provided to reduce the misconceptions involved. Provision of free services and more participation in education and sensitization from the healthcare providers should also be done.

\section{Conflicts of Interest}

The authors declare no conflicts of interest regarding the publication of this paper.

\section{References}

[1] Lea, J.S. and Lin, K.Y. (2012) Cervical Cancer. Obstetrics and Gynecology Clinics of North America, 39, 233-253. https://doi.org/10.1016/j.ogc.2012.02.008

[2] Ntekim, A. (2012) Cervical Cancer in Sub Sahara Africa. In: Topics on Cervical Cancer with an Advocacy for Prevention. https://doi.org/10.5772/27200

[3] Gatumo, M., Gacheri, S., Sayed, A.R. and Scheibe, A. (2018) Women's Knowledge and Attitudes Related to Cervical Cancer and Cervical Cancer Screening in Isiolo and Tharaka Nithi Counties, Kenya: A Cross-Sectional Study. BMC Cancer, 18, Article No. 745. https://doi.org/10.1186/s12885-018-4642-9

[4] Alfaro, K.M., Gage, J.C., Rosenbaum, A.J., Ditzian, L.R., Maza, M., Scarinci, I.C. and Cremer, M.L. (2015) Factors Affecting Attendance to Cervical Cancer Screening among Women in the Paracentral Region of El Salvador: A Nested Study within the CAPE HPV Screening Program Chronic Disease Epidemiology. BMC Public Health, 15, Article No. 1058. https://doi.org/10.1186/s12889-015-2360-7

[5] Weng, Q., Jiang, J., Haji, F.M., Nondo, L.H. and Zhou, H. (2020) Women's Knowledge of and Attitudes toward Cervical Cancer and Cervical Cancer Screening in Zanzibar, Tanzania: A Cross-Sectional Study. BMC Cancer, 20, Article No. 63. https://doi.org/10.1186/s12885-020-6528-X

[6] Sewali, B., Okuyemi, K.S., Askhir, A., Belinson, J., Vogel, R.I., Joseph, A. and Ghebre, R.G. (2015) Cervical Cancer Screening with Clinic-Based Pap Test versus Home HPV Test among Somali Immigrant Women in Minnesota: A Pilot Randomized Controlled Trial. Cancer Medicine, 4, 620-631.

https://doi.org/10.1002/cam4.429

[7] Herweijer, E., Feldman, A.L., Ploner, A., Arnheim-Dahlström, L., Uhnoo, I., Netterlid, E., et al. (2015) The Participation of HPV-Vaccinated Women in a National Cervical Screening Program: Population-Based Cohort Study. PLoS ONE, 10, e0134185. https://doi.org/10.1371/journal.pone.0134185

[8] World Health Organization (2014) Comprehensive Cervical Cancer Control: A Guide to Essential Practice. World Health Organization, Geneva.

[9] Rosser, J.I., Njoroge, B. and Huchko, M.J. (2015) Knowledge about Cervical Cancer Screening and Perception of Risk among Women Attending Outpatient Clinics in Rural Kenya. International Journal of Gynaecology and Obstetrics, 128, 211-215. https://doi.org/10.1016/j.ijgo.2014.09.006 
[10] Sudenga, S.L., Rositch, A.F., Otieno, W.A. and Smith, J.S. (2013) Knowledge, Attitudes, Practices, and Perceived Risk of Cervical Cancer among Kenyan Women: Brief Report. International Journal of Gynecological Cancer, 23, 895-899. https://doi.org/10.1097/IGC.0b013e31828e425c

[11] Tay, K., Tay, S.K., Tesalona, K.C., Rashid, N.M.R., Tai, E.Y.S. and Najib, S.J.M. (2015) Factors Affecting the Uptake of Cervical Cancer Screening among Nurses in Singapore. International Journal of Gynecology and Obstetrics, 130, 230-234. https://doi.org/10.1016/j.ijgo.2015.03.037

[12] Arbyn, M. and European Commission (2008) European Guidelines for Quality Assurance in Cervical Cancer Screening. Office for Official Publications of the European Communities, Luxembourg.

[13] Rasul, V.H., Cheraghi, M.A. and Moghdam, Z.B. (2016) Barriers to Cervical Cancer Screening among Iraqi Kurdish Women: A Qualitative Study. Acta Medica Mediterranea, 32, 1249-1256.

[14] Mupepi, S.C., Sampselle, C.M. and Johnson, T.R. (2011) Knowledge, Attitudes, and Demographic Factors Influencing Cervical Cancer Screening Behavior of Zimbabwean Women. Journal of Women's Health, 20, 943-952.

https://doi.org/10.1089/jwh.2010.2062

[15] Guilfoyle, S., Franco, R. and Gorin, S.S. (2007) Exploring Older Women's Approaches to Cervical Cancer Screening. Health Care for Women International, 28, 930-950. https://doi.org/10.1080/07399330701615358

[16] Were, E., Nyaberi, Z. and Buziba, N. (2011) Perceptions of Risk and Barriers to Cervical Cancer Screening at Moi Teaching and Referral Hospital (MTRH), Eldoret, Kenya. African Health Sciences, 11, 58-64.

[17] Mugenda, O.M. and Mugenda, A.G. (2003) Research Methods, Quantitative and Qualitative Approaches. ACT, Nairobi.

[18] Fisher, A.A., Laing, J.E., Stoeckel, J.E. and Townsend, J.W. (1998) Handbook for Family Planning Operations Research Design. 2nd Edition, Population Council, New York.

[19] Bosgraaf, R.P., Ketelaars, P.J.W., Verhoef, V.M.J., Massuger, L.F.A.G., Meijer, C.J.L.M., Melchers, W.J.G. and Bekkers, R.L.M. (2014) Reasons for Non-Attendance to Cervical Screening and Preferences for HPV Self-Sampling in Dutch Women. Preventive Medicine, 64, 108-113. https://doi.org/10.1016/j.ypmed.2014.04.011

[20] Rosser, J.I., Hamisi, S., Njoroge, B. and Huchko, M.J. (2015) Barriers to Cervical Cancer Screening in Rural Kenya: Perspectives from a Provider Survey. Journal of Community Health, 40, 756-761. https://doi.org/10.1007/s10900-015-9996-1

[21] Sandeep, S. (2012) Factors Influencing Uptake of Cervical Cancer Screening among Women in India: A Hospital based Pilot Study. Journal of Community Medicine \& Health Education, 2, 1-17.

[22] Aminisani, N., Fattahpour, R., Abedi, L. and Shamshirgaran, S.M. (2016) Determinants of Cervical Cancer Screening Uptake in Kurdish Women Living in Western Iran, 2014. Asian Pacific Journal of Cancer Prevention, 17, 3761-3765.

[23] Rosser, J.I., Zakaras, J.M., Hamisi, S. and Huchko, M.J. (2014) Men's Knowledge and Attitudes about Cervical Cancer Screening in Kenya. BMC Women's Health, 14, Article No. 138. https://doi.org/10.1186/s12905-014-0138-1

[24] Arbyn, M., Castellsagué, X., de sanjosé, S., Bruni, L., Saraiya, M., Bray, F. and Ferlay, J. (2011) Worldwide Burden of Cervical Cancer in 2008. Annals of Oncology, 22, 2675-2686. https://doi.org/10.1093/annonc/mdr015 
[25] Gebreegziabher, M., Asefa, N.G., Berhe, S., Gebreegziabher, M., Asefa, N.G. and Berhe, S. (2016) Factors Affecting the Practices of Cervical Cancer Screening among Female Nurses at Public Health Institutions in Mekelle Town, Northern Ethiopia, 2014: A Cross-Sectional Study. Journal of Cancer Research, 2016, Article ID: 4743075. https://doi.org/10.1155/2016/4743075 


\section{Appendix I. Questionnaire for the Study Participants}

Instructions

Serial No

1) Do not write your name.

2) Fill all the relevant sections

3) Use a tick $(\sqrt{ })$ where applicable

\section{Part A}

1) Age:
a) 15 - 18 years
b) 19 - 22 years
c) 23 - 25 years
2) Gender:
a) Male
]
b) Female [ ]

3) Level of Education:

a) Primary

b) Secondary

c) College

4) Occupation:
a) Student
b) Farmer
c) Business
d) Employed

5) Age at menarche:

6) Marital status

a) Single

b) Married

c) Divorced

d) Widowed

7) Age at first sexual intercourse:

8) Number of sexual partners:

\section{SECTION B: KNOWLEDGE ON CERVICAL CANCER SCREENING}

9) Have you ever heard of cervical cancer?
a) Yes
b) No

10) If Yes, Briefly explain what you understand about cervical cancer

11) Where did you get the information about cervical cancer screening?
a) Friends
b) Family member
c) Media channels e.g TV, newspaper [ ]
d) Healthcare providers/Hospital [ ]
e) Other (Please specify) 
12) When should a woman go for cervical cancer screening?

a) When starting menstruation

b) When married

c) When sexually active

13) How often should a woman go for cervical cancer screening?

a) Monthly

b) Annually

c) Every 2 years

d) As per HCP instructions

e) Do not know

14) Have you ever been screened for cervical cancer before?
a) Yes
b) No

15) If Yes, Explain what happens?

16) What made you seek screening services?

17) What are the benefits associated with cervical cancer screening

SECTION C: BELIEFS ABOUT CERVICAL CANCER SCREENING

18) Do you agree/concur that cervical cancer screening is helpful?
a) I agree
b) I disagree
19) If Yes in 18 above, explain your reasons

20) If No in 18 above, explain your reasons 


\section{SECTION D: BARRIERS THAT HINDER CERVICAL CANCER SCREENING}

21) What are some of the barriers that hinder women aged 25 years and below from seeking cervical cancer screening services? Please tick appropriately, you can tick more than one time

Lack of services for screening

Inadequate knowledge by women

Lack of money to go for screening

Negative attitude towards screening

Cultural beliefs against screening

Religious beliefs against screening

Lack of male/family support

Male spouse disapproval

Other (Specify).

22) What are some of the things you propose that can be done to improve the practice of cervical cancer screening? 